\title{
JUVENTUDES ESCOLARIZADAS, SENTIDOS Y METÁFORAS SOBRE EL LICEO PÚBLICO MUNICIPAL EN EL CHILE CONTEMPORÁNEO
}

\author{
WALTER MOLINA CHÁVEZ*
}

\begin{abstract}
RESUMEN
La sociedad chilena en los últimos cuarenta años ha sido objeto de un conjunto de transformaciones estructurales y junto con las cuales, se ha producido una profunda reconfiguración de los modos en que los sujetos se posicionan en estas nuevas condiciones estructurales y subjetivas. En este artículo, interesa explorar la manera en que estas transformaciones económicas, políticas y culturales, han ido complejizando el tradicional modo de relación de las y los jóvenes con el campo educativo. Específicamente queremos abordar cómo los estudiantes secundarios que asisten a los liceos municipales públicos en Chile se representan metafóricamente esta institución educativa, la cual en diversos momentos del desarrollo histórico de la sociedad chilena fue un ámbito privilegiado de integración social y que actualmente ha devenido en un poderoso mecanismo de exclusión social.
\end{abstract}

PALABRAS CLAVE: JUVENTUDES, EDUCACIÓN, METÁFORAS

* Trabajador social, doctor en ciencias de la educación. Académico de la Universidad de Magallanes, Carrera de Trabajo Social, Punta Arenas, Chile. Este artículo forma parte del proyecto «Juventudes. Transformaciones socioeconómicas, sociopolíticas y socioculturales de las y los jóvenes en el Chile contemporáneo». Programa de Investigación Asociativa Conicyt NSOC1108. E-Mail: walter.molina@umag.cl. 


\title{
JUVENTUDES ESCOLARIZADAS E METAFORAS SOBRE O LICEO PUBLICO MUNICIPAL NO CHILE CONTEMPORÂNEO
}

\begin{abstract}
RESUMO
A sociedade chilena nos últimos 40 anos, passou por uma série de mudanças estruturais e, junto com elas, houve uma profunda reconfiguração das formas em que os sujeitos são posicionados nestas novas condições estruturais e subjetivas. Neste artigo, estamos interessados em explorar o jeito como estas transformaçoes econômicas, políticas e culturais, tem influido nas relacoes entre os jovenes e sua educaçao. Especificamente, como os alunos da secundária de escolas públicas dos municípios de Chile são representados metaforicamente en esta instituição educacional, que em vários momentos do desenvolvimento histórico da sociedade chilena foi de uma integração social privilegiada e agora tornou-se um poderoso mecanismo de exclusão social.
\end{abstract}

PALAVRAS CHAVE: JUVENTUDE, EDUCAÇAO, METAFORAS

\section{EDUCATED YOUTH AND METAPHORS ABOUT PUBLIC MUNICIPAL SCHOOL IN CONTEMPORARY CHILE}

\begin{abstract}
Chilean society, in the last forty years, has undergone a series of structural changes, and along with them, there has been a deep reconfiguration of the ways in which subjects are positioned in these new structural and subjective conditions. In this article, we are interested in exploring the manner in which these economic, political and cultural changes have been making complex the traditional way of relationship between the youth and the educational field. Specifically, how secondary students who attend municipal-public schools in Chile, metaphorically represent this educational institution which at different moments of historical development of Chilean society was a privileged field of social integration and which nowadays has become a powerful mechanism of social exclusion.
\end{abstract}

KEY WORDS: YOUTH, EDUCATION, METAPHORS 


\section{INTRODUCCIÓN}

TRADICIONALMENTE LOS SISTEMAS EDUCATIVOS nacionales se han configurado en torno a dos ejes de definiciones estratégicas. Por una parte, la emergencia de ciertos supuestos sobre niñez, adolescencia y juventud en seno de las sociedades; lo cual implica ciertas distinciones o representaciones sobre quiénes son los individuos, sujetos y actores claves de las instituciones escolares. Por otra parte, existen determinadas visiones de la sociedad y de los campos de «lo social» a los cuales dichos actores deben integrarse. Al respecto, Garretón (2000) plantea que históricamente el sistema educacional chileno se estructuró desde comienzos del siglo XX guiado por el supuesto que tanto la «escuela pública» (primaria) como el «liceo público» (secundaria) — como expresión del ideal liberal republicano- eran los espacios institucionales privilegiados para promover la integración a la sociedad. De este modo, la escolarización primaria y secundaria se constituyó en el mecanismo privilegiado y directo para incorporarse a la esfera del trabajo asalariado o productivo. Sin embargo, en la actualidad ambos supuestos han perdido vigencia debido principalmente a las profundas transformaciones en los diversos ámbitos de la vida social: lo socioeconómico, lo sociopolítico y lo sociocultural y la devaluación social de la escolarización obligatoria. Se trata de cambios tanto en la estructura de la sociedad así como a nivel de la subjetividad, cambios han hecho emerger nuevas formas de relación del individuo con la educación, el trabajo, la familia, entre otras tendencias de cambio actualmente en curso.

En este contexto de cambios estructurales en las sociedades contemporáneas se producen simultáneamente profundos y complejos cambios representacionales a nivel de la subjetividad de los sujetos socioeducativos, particularmente a nivel de la experiencia escolar de las y los jóvenes que asisten cotidianamente al liceo público municipal en Chile y específicamente, se reconfiguran los modos en que éstos se representan metafóricamente esta institución educativa, su significado social, sus sentidos educativos y sus potenciales aportes a sus trayectorias educacionales y/o laborales. Las reflexiones propuestas en este artículo esperan contribuir a resituar la pregunta por las configuraciones de sentido sobre la escuela secundaria en Chile y las subjetividades emergentes sobre los procesos de escolarización secundaria (obligatoria, masiva y segmentada) chilena en los inicios del siglo XXI. 


\section{JUVENTUDES Y PROCESOS DE ESCOLARIZACIÓN SECUNDARIA EN EL CHILE CONTEMPORÁNEO}

En Chile, durante las últimas dos décadas hemos evidenciado un significativo aumento en la cantidad de estudios sobre la juventud como grupo social altamente diferenciado (Duarte, 1996; Sandoval, 2002; Zarzuri y Ganter, 2002; Dávila, 2005; Krauskopf, 2011; Ruiz, et al., 2011), lo cual ha permitido la apertura de un campo de investigación que de un modo u otro ha influido en el diseño y renovación de las políticas públicas orientadas a este segmento de la población chilena. Desde un punto de vista teórico-analítico, la opción más frecuente en dichos estudios ha sido describir la «condición juvenil» en función de diversas variables de análisis, como la edad, situación laboral, niveles de escolaridad, factores de exclusión/inclusión social o alternativamente, identificar sus características identitarias, expresiones culturales y prácticas contraculturales.

De acuerdo a Aguilera (2009) a comienzos de los años noventa la juventud se constituyó en un «cuerpo social focalizado» para intervenir desde el aparato estatal y en consecuencia, los estudios de juventud se orientaron preferentemente a establecer diagnósticos descriptivos que permitieran promover procesos de integración social de los jóvenes de ambos sexos en un contexto sociopolítico de transición de una dictadura (1973-1989) a un régimen democrático (1990-2010). Lo anterior, explica que una parte importante de los estudios se realizaran alrededor de las instituciones educativas (liceo público municipal) y de forma más general en torno a los emergentes procesos de escolarización secundaria obligatoria (Edwards et al., 1995; Salinas y Franssen,1997; Cerda et al., 2000; Oyarzún et al., 2001; Baeza, 2001) y más concretamente aún, sobre los conflictos existentes entre la cultura escolar y las culturas juveniles; lo cual a su vez nos remite a una tensión permanente - aunque no siempre explícita - entre tres actores estratégicos de la enseñanza media o secundaria: profesores (adultos), alumnos (jóvenes) y familias (padres y apoderados). Al respecto, algunos autores (Cerda et al., 2000; Molina y Sandoval, 2006) señalan que esta tensión se produciría por una tendencia implícita que lleva a la escuela/liceo — en tanto institución social reproductora de un orden social - a cerrarse respecto de las vivencias o experiencia social de los propios estudiantes. Una expresión concreta de este cierre, es homogeneizar a los jóvenes estudiantes de ambos sexos en la categoría «alumnos»; es decir, todos iguales, todos con las mismas racionalidades, enmarcados en un mismo 
régimen de enseñanza y disciplina escolar que configura un orden escolar instituido.

En este contexto socioeducativo, las significaciones, sentidos y experiencias que desde este «mundo exterior» al liceo/escuela configuran los y las jóvenes (orden instituyente), son consideradas por la institución escolar como aspectos residuales y hasta disfuncionales a la dinámica escolar; llegando a poner en cuestión la propia capacidad socializadora de dichas instituciones educativas. Los autores mencionados, destacan el hecho de que los procesos de escolarización en nuestro país aún no han incorporado de modo relevante alguno de los componentes constitutivos de la subjetividad juvenil en el quehacer formativo; sus intereses, expectativas de desarrollo sociopersonal, configuración de nuevos sentidos educativos y las diversas formas de expresividad juvenil. Por ello, resulta relevante indagar en las tensiones que se producen en torno a los procesos de escolarización secundaria desde la propia experiencia escolar de los y las jóvenes en el Chile actual; es decir, se trata de construir conocimiento social sobre las juventudes escolarizadas.

En el presente estudio, y siguiendo lo planteado por Duarte (2000), se hará referencia a la noción de «juventudes» para designar a un grupo social diverso que puede ser abordado tanto desde variables demográficas, económicas y culturales; pero que en ningún caso es homogéneo o reductible a una de dichas variables de estudio y mucho menos, al mero ejercicio de un rol social específico y contingente como sería el rol de estudiante, trabajador, hijo, ciudadano, entre otros. De modo complementario, a juicio de Dubet (2004) en la actualidad, tanto por razones demográficas como sociales, la juventud se encuentra sometida a continuos cambios en el seno de las sociedades. En virtud de dichos procesos de transformación, las juventudes están empezando a extenderse más allá de los límites impuestos por la tradición occidental moderna. En este contexto, para Dubet (2004) el objeto de estudio específico de la «sociología de la juventud» correspondería a las «relaciones intergeneracionales» más allá de la posibilidad metodológica de abordar dicha «condición social» a partir de los diferentes ámbitos, instituciones, políticas y contextos singulares en los cuales se desarrolla la vida juvenil contemporánea.

Por otra parte, como señala Gimeno (2001), los procesos de escolarización obligatoria se han constituido en una de las características antropológicas centrales de las sociedades contemporáneas, ya sea ésta entendida como institucionalización o como configuración de imagi- 
narios sociales. En ambos casos sus efectos se expanden hacia amplios grupos sociales. Como la «representación social» comprende un conglomerado simbólico de significados, valores, aspiraciones y expectativas de comportamiento que impactan cotidianamente en las formas de pensar, de querer y de relacionarse con los miembros de la sociedad, estas imágenes actúan de manera implícita o explícita en la formación de las aspiraciones que tenemos — como individuos y como sociedad - para poder llegar a ser diferentes a lo que somos. Este mismo autor sostiene que esa representación, una vez creada, es transmitida y transformada de manera consciente por la dinámica social, hasta aparentar ser algo dado y espontáneo sobre lo que conviene siempre discutir, aunque sea sólo para reafirmar su valor, insuflando nueva fuerza a esa representación. De este modo, la escolarización se ha ido naturalizando a tal extremo que pareciera ocurrir más por necesidad que por voluntad y se ha transformado en una responsabilidad de los actores sociales que la constituyen. En una perspectiva de análisis más general, Gimeno (2001) sostiene que ingresar, estar o permanecer por un tiempo en cualquier tipo de institución escolar, es una experiencia tan natural y cotidiana que ni siquiera tomamos conciencia de la razón de ser de su existencia, de la contingencia de la misma, de su posible provisionalidad en el tiempo, de las funciones que cumplió, cumple o podría cumplir, ni de los significados que tiene en la vida de las personas, en las sociedades y en las culturas. Por ello, se considera relevante indagar tanto en los sentidos de la educación secundaria como en las metáforas que construyen los jóvenes de ambos sexos sobre el liceo público municipal en Chile, en tanto principal institución prestadora de servicios educativos para la mayor parte de la población de menores ingresos socioeconómicos. Es importante destacar, que el estudio de dichas metáforas adquieren una importancia especial en un contexto histórico en que las demandas ciudadanas por una educación pública, gratuita y de calidad han copado la agenda de las políticas públicas en Chile de cara al siglo XXI.

\section{LA ESCOLARIZACIÓN SECUNDARIA: SUS SENTIDOS Y METÁFORAS}

Uno de los principales desafíos de la escuela secundaria contemporánea es orientarse hacia la construcción de sujetos comprometidos con los principios de ciudadanía y contribuir a la gestión democrática de la sociedad. Para Touraine (1997), la escuela debe ayudar a unir dos 
mundos que actualmente tensionan a los jóvenes. Por una parte, el mundo/sistema que condiciona sus posibilidades materiales de realización personal y social, principalmente través de los mercados del trabajo y de productos (consumo). Y por otra parte, el universo simbólico que constituye la cultura de los jóvenes, el cual es co-construido desde los medios de comunicación de masas, las interacciones con sus pares y las industrias de consumo cultural. Como contraparte de estos procesos, desde la ciudadanía emerge un profundo reclamo social que dice relación con la necesidad de (re)orientar «los procesos de escolarización secundaria en pos de producir sentidos» educativos más integrales, más inclusivos con respecto a las culturas juveniles y más igualitarias en términos de acceso y calidad académica de la oferta educativa. De modo tal, que la educación y la escuela/liceo (público municipal) no sólo se convierta en un vehículo de transmisión cultural y/o habilitación para el trabajo productivo o asalariado; sino por el contrario se constituya en un genuino espacio/lugar social y formativo desde el cual se configuren diversos horizontes de sentidos, tanto educativos como sociales, que contribuyan a la democratización de la sociedad chilena contemporánea.

Recientemente, y desde una perspectiva más global, Sobrero (2011) sostiene que al analizar las configuraciones de sentido en torno a la educación pública en Chile en los discursos de la política educativa, implementada en el período 1990-2007, se puede observar que se han producido tanto continuidades como desplazamientos de sentido en torno al significado de la educación pública, lo cual ha dado origen a «un conjunto complejo y heterogéneo de interacciones que configuran relaciones de poder en el que se enfrentan relatos y visiones diversas de las finalidades de las instituciones educativas» (Sobrero, 2011). Así concluye que desde las políticas educativas se promueven sentidos que sugieren un tratamiento indiferenciado entre la esfera pública y la esfera privada, a partir de lo cual la educación pública quedaría subsumida a una «racionalidad economicista» que restringe su campo de acción a la gestión de los recursos e insumos internos del sistema educativo; enmarcando con ello la diversidad de experiencias subjetivas de los actores educativos, tanto dentro como fuera del espacio escolar. Por ello, la misma autora sostiene lo siguiente:

La defensa de la educación pública resulta una problemática que en ningún modo se agota en discusiones vinculadas a sistemas más o menos descentralizados, a una gestión más o menos eficiente de recursos o 
a la calidad de los aprendizajes medidos en base a test estandarizados. Más bien, hacer pública la educación, requiere un nuevo modo de pensarla que recupere su carácter político, permitiendo incorporar en el régimen de la mirada su relación con el sistema de regulación social en el que se inscribe y al cual promueve (Sobrero, 2011:183).

Por su parte, Molina (2008) en el marco de una investigación doctoral, ha identificado y descrito un conjunto de cuatro configuraciones de sentido de la educación secundaria pública-municipal en Chile desde la perspectiva de la experiencia escolar de los estudiantes: i) «prepararte para el futuro»; ii) «desarrollarte como persona»; iii) «tener más cultura» y iv) «vivir la experiencia/etapa». Se sostiene así que dichas representaciones sociales estarían mediando su experiencia escolar al interior de los liceos municipales a los que asisten los jóvenes; obstaculizando o facilitando con ello el logro de una educación secundaria con alta calidad académica, relevancia social (y personal) y con resultados de aprendizaje que contribuyan a su inserción social postsecundaria.

Desde otro ángulo de análisis, esta diversidad de configuraciones de sentido identificadas en Chile se corresponden con lo que Kessler (2002) denomina «una experiencia escolar fragmentada» en la escuela secundaria Argentina; es decir, la existencia al interior de un mismo nivel educativo de «diversos modos de vivir y experimentar los procesos de escolarización secundaria obligatoria». Más concretamente, y en los términos planteados por Tenti (2000) para el caso de la escuela secundaria argentina, se han configurado tres horizontes de sentido: a) como obligatoriedad social (y jurídica) de asistir a la enseñanza secundaria; b) como la posibilidad estratégica-instrumental de acceder a mejores condiciones de vida en el futuro; y c) el sentido como amor al conocimiento y al aprendizaje como valores en sí mismos (Tenti, 2000). Como señala este mismo autor; estas tres disposiciones ideal típicas descritas por la literatura no están aleatoriamente distribuidas en la población escolar; sino que por el contrario son el producto de un conjunto de factores interrelacionados. Entre ellos, se destacan los factores culturales, las trayectorias sociales de los jóvenes y las posiciones que ocupan las personas en la estructura social respectiva.

En este marco analítico - y como una forma de profundizar en el análisis de los significados sociales de los procesos de escolarización secundaria en Chile - hemos seleccionado una variedad de metáforas enunciadas por los y las estudiantes en el contexto de entrevistas en 
profundidad, las que dan cuenta de la valorización sobre el liceo público municipal. Al respecto, y desde un punto de vista teórico, cabe señalar que estas expresiones se caracterizan por el carácter analógico o comparativo del lenguaje utilizado en su formulación, constituyéndose de este modo en una manera simbólica de valorizar o tomar posición frente a un objeto o campo representacional, como lo es en este caso, el liceo público municipal. A través de estas expresiones metafóricas, los estudiantes simbolizan (y valorizan) de una manera diferente, tanto el sentido educativo de la enseñanza media o secundaria en Chile, así como específicamente el aporte de la institución que la imparte, remitiendo de este modo a las imágenes que ellos activan — durante las entrevistas - cuando se refieren en su discurso a un eje semántico (espacial) denominado «liceo municipal».

Considerando lo anteriormente planteado, es relevante realizar un análisis específico de dichas metáforas y comparaciones enunciadas por estudiantes secundarios que asisten a liceos municipales de en la ciudad de Santiago, Chile. Estas «figuras retóricas» han sido destacadas por su capacidad simbólica para expresar aspectos referidos a la experiencia cotidiana de los sujetos. Al respecto, diversos autores como Lakoff y Jonhson (2001) plantean que las metáforas tienen sus raíces en la experiencia «física» y «cultural»; por lo que no pueden entenderse, ni siquiera representarse adecuadamente, en forma independiente de su fundamento en la experiencia personal y social de los sujetos que las enuncian.

Desde una perspectiva de análisis general, Lakoff y Johnson (2001) proponen enfatizar la inseparabilidad de las metáforas de su base experiencial, integrando esta base dentro de la representación misma. Como podemos observar, el papel de la experiencia es fundamental para la comprensión del funcionamiento de las diferentes metáforas, que pueden generarse a partir de un mismo dominio. En nuestro caso, pudimos observar que el espacio social denominado «liceo municipal» activa metáforas de variado carácter: el liceo es como un computador, una planta, un templo, un refugio, etcétera. Estas metáforas se basan en la elaboración de una diversidad de ámbitos de la experiencia social de los estudiantes.

Por una perspectiva más teórica, la importancia de abordar la metáfora en el análisis «lo social», según Munby (1988), radica en el hecho de que estructuran - parcialmente - los conceptos que usamos cotidianamente y esta estructura se refleja en nuestro lenguaje literal. Por otra parte, tienen implicaciones en cuanto hacen coherente ciertos 
aspectos de nuestra experiencia, que de otro modo resultarían incoherentes o incomprensibles. De este modo se pueden crear realidades, especialmente sociales, y convertirse en guía para la acción de los sujetos que las configuran. Este sería el caso de las metáforas o comparaciones sobre el liceo municipal que construyen cotidianamente los estudiantes.

En este sentido, las investigaciones que han optado por analizar el lenguaje figurativo o metafórico junto con aplicar la noción de «metáfora», señalan que éstas no sólo deben describirse en términos proposicionales, pues el lenguaje figurativo realizaría una función importante cuando se trata de describir las percepciones y experiencias. Igualmente, se afirma que las metáforas constituyen poderosas herramientas para comprender el pensamiento y las acciones de los sujetos en contextos sociales y discursivos diversos (Munby, 1988). Por ello, nos parece relevante realizar el análisis de las metáforas sobre el liceo público municipal, y con ello, dar cuenta de su capacidad de imaginar y crear realidad a través del lenguaje, proporcionarnos una nueva comprensión de la experiencia de los estudiantes secundarios que asisten a escuelas públicas y de sus percepciones sobre estas instituciones educativas. Es decir, en el sentido señalado Lakoff y Johnson (2001) nos ayudan a dar nuevo significado a nuestras actividades, experiencias pasadas y cotidianas. Así como también nos permiten (re)plantearnos lo que sabemos y creemos sobre dichas experiencias, prácticas sociales y educativas. En el presente análisis, se han seleccionado tanto las «metáforas» como «comparaciones», ya que, aún cuando éstas últimas han sido tradicionalmente consideradas como figuras literarias diferenciadas, en lo central son expresiones lingüísticas cuyo significado expresa la relación (la forma A es como B) y describen semejanzas relevantes en la experiencia de las personas (Lakoff y Johnson, 1981) que nos permiten evidenciar, al final de cada entrevista, la existencia de una determinada organización simbólica y una lógica subyacente al contenido representacional, tanto sobre el sentido de la escolarización secundaria así como las valorizaciones (positivas o negativas) que los estudiantes construyen sobre el «liceo municipal» en cuanto expresión tangible de los procesos educativos que se promueven desde la política educativa pública. 


\section{ENFOQUE MATERIAL Y MÉTODO DE INVESTIGACIÓN}

En un contexto de diversidad paradigmática, hemos optado por un enfoque cualitativo por cuanto esta perspectiva de análisis supone adentrarse en la experiencia social de los sujetos; bajo una actitud fenomenológica, de respeto, apertura y siempre atentos a escuchar los relatos de los sujetos entrevistados.

\section{a) Estrategia de muestreo utilizada en el estudio}

La investigación utilizó una estrategia de «muestreo estructural» (Canales, 1994) para seleccionar los liceos estudiados. Idéntico procedimiento se utilizó para seleccionar a los estudiantes entrevistados. En este contexto metodológico, la muestra del presente estudio se estructuró a partir de los siguientes criterios de elección definidos por el investigador:

- Que los estudiantes cursen cuarto año de enseñanza media en liceos municipales localizados en cuatro comunas de la Región Metropolitana, Chile.

- Que los participantes estén distribuidos proporcionalmente entre hombre y mujeres. En cada uno de los liceos se seleccionó a cuatro hombres y cuatro mujeres.

- Se seleccionaron cuatro comunas y respectivamente cuatro liceos «representativos», de diferentes estratos socioeconómicos.

Las características más relevantes de los establecimientos son las siguientes:

\begin{tabular}{|l|l|c|c|c|}
\hline Establecimiento & Comuna & Dependencia** & $\begin{array}{c}\text { Grupo } \\
\text { Socioeconómico* }\end{array}$ & $\begin{array}{c}\text { Número } \\
\text { Entrevista }\end{array}$ \\
\hline Liceo 4 (LMSR) & San Ramón & MD & A (Bajo) & 8 \\
\hline Liceo 3 (LMLP) & La Pintana & MD & B (Medio Bajo) & 8 \\
\hline Liceo 2 (LMLF) & La Florida & MC & C (Medio) & 8 \\
\hline Liceo 1 (LMLC) & Las Condes & MCC & D (Medio alto) & 8 \\
\hline & & & & $\mathbf{3 2}$ \\
\hline
\end{tabular}

(*) El grupo socioeconómico al que pertenece el establecimiento sigue la clasificación del SIMCE: A (bajo), B (medio-bajo), C (medio), D (medio-alto) y E (alto). Cabe señalar que no existen establecimientos municipales que atiendan población escolar del estrato socioeconómico alto.

(**) Dependencia: es el tipo de administración. MD: Municipal sin financiamiento compartido. MC: Corporación municipal sin financiamiento compartido. MCC: Corporación municipal con financiamiento compartido. 


\section{b) Técnicas de producción y análisis de datos}

La principal herramienta de producción de datos fue la entrevista en profundidad, por cuanto esta técnica de investigación social tiene la potencialidad de acceder a los significados que los actores sociales investigados construyen sobre el/los sentido(s) de la enseñanza media municipal.

Por otra parte, el material textual producido a través de las entrevistas fue analizado con herramientas provenientes de la semántica estructural (Greimas, 1971). Como sabemos, este autor integra entre sus supuestos teóricos y metodológicos diversos aspectos de la lingüística estructural (Saussure, 1945). Entre los conceptos que Greimas recoge y aplica en su modelo de análisis semántico, encontramos aspectos centrales como los referidos al signo lingüístico, a su naturaleza y a sus relaciones con otros signos.

De este modo, Greimas (1971) plantea, que la «lengua está hecha de oposiciones», por lo tanto de continuidades y discontinuidades. En este contexto, es posible comprender la concepción de estructura que define del siguiente modo: «es la presencia de dos términos y de la relación entre ellos existente»(Greimas, 1971:28). Esta distinción implica dos consecuencias para el análisis semántico: un solo términoobjeto no conlleva significación y la significación presupone la existencia de la relación; es decir, la condición necesaria de la significación es la aparición de la relación entre dos términos. En el plano lingüístico, a propósito de la relación, es posible identificar por tanto dos términos que poseen algo en común, dos términos en que puedan identificarse diferencias y la identificación de la doble naturaleza de la relación entre dos términos: conjunción y disyunción (continuidad y diferencia). Lo anterior permite a Greimas definir las estructuras elementales del sistema semántico como un tipo de relación entre dos términos objeto. El hecho de que los términos por sí mismos no conllevan significación, se sustenta en una concepción de lengua en la cual a ésta no se la considera como un sistema de signos, sino como una trabazón de estructuras de significación.

Como una forma de capturar esa red de significados que se tejen alrededor del liceo publico municipal en Chile y la consiguiente configuración de sentidos sobre la escolarización secundaria obligatoria por parte de los estudiantes que asisten a este tipo de instituciones educativas, se ha optado por una aproximación a dicho proceso de significación a través del estudio de las metáforas que construyen los 
estudiantes. Y tal como señala Lakoff y Johnson (2001), la experiencia juega un rol clave en la comprensión de su funcionamiento en relación a diferentes ámbitos de la experiencia social y escolar de los estudiantes. Como se conceptualizó anteriormente, las metáforas corresponden a figuras retóricas que tienen la capacidad de tematizar, conceptualizar, dar coherencia y sentido a la experiencia de los actores sociales; y por ello a continuación analizaremos las metáforas elaboradas por los estudiantes sobre el liceo municipal.

\section{ANÁLISIS DE METÁFORAS SOBRE EL LICEO MUNICIPAL EN EL DISCURSO DE LOS Y LAS JÓVENES ESTUDIANTES SECUNDARIOS}

\section{a) El lugar como eje de análisis de las metáforas sobre el liceo municipal}

En los textos producidos por los estudiantes de enseñanza media emerge un eje de significados que visibiliza a la escuela como el espacio social desde donde se realiza la construcción de significados y sentidos de la enseñanza media municipal. Al respecto, cabe señalar que para Garrido (2009) el mundo educativo (y de la escuela/liceo) puede ser entendido como una forma espacial lugarizada. Es decir, el espacio educativo se tornaría «lugar» cuando en las prácticas educativas emergen formas más o menos conscientes de potenciar los sentidos de subjetivación y socialización de quienes participan en una relación educativa.

Para este mismo autor, el «lugar» no sólo se puede entender en referencia al espacio geográfico, sino que además se entiende como una posibilidad de comprenderlo, simultáneamente, como una posibilidad de tematizar la interrelación entre los seres humanos y el medio (geográfico) en el que habitan cotidianamente. En este contexto de análisis, sostenemos que el liceo municipal, en tanto expresión tangible de los procesos educativos que allí ocurren, se constituye en un poderoso mecanismo de mediación de los sentidos educativos y significados sociales sobre la educación secundaria en general; así como específicamente sobre el «lugar» en que ocurre el encuentro cotidiano entre sus actores estratégicos: estudiantes y profesores

En este marco, es importante destacar que en los discursos de los estudiantes sobre el liceo municipal emerge rápidamente una oposición semántica central: liceo/sociedad. A partir de esta disyunción espacial se acoplan una serie de estructuras semánticas paralelas que 
dan cuenta de los diferentes términos que adopta dicha oposición semántica de base.

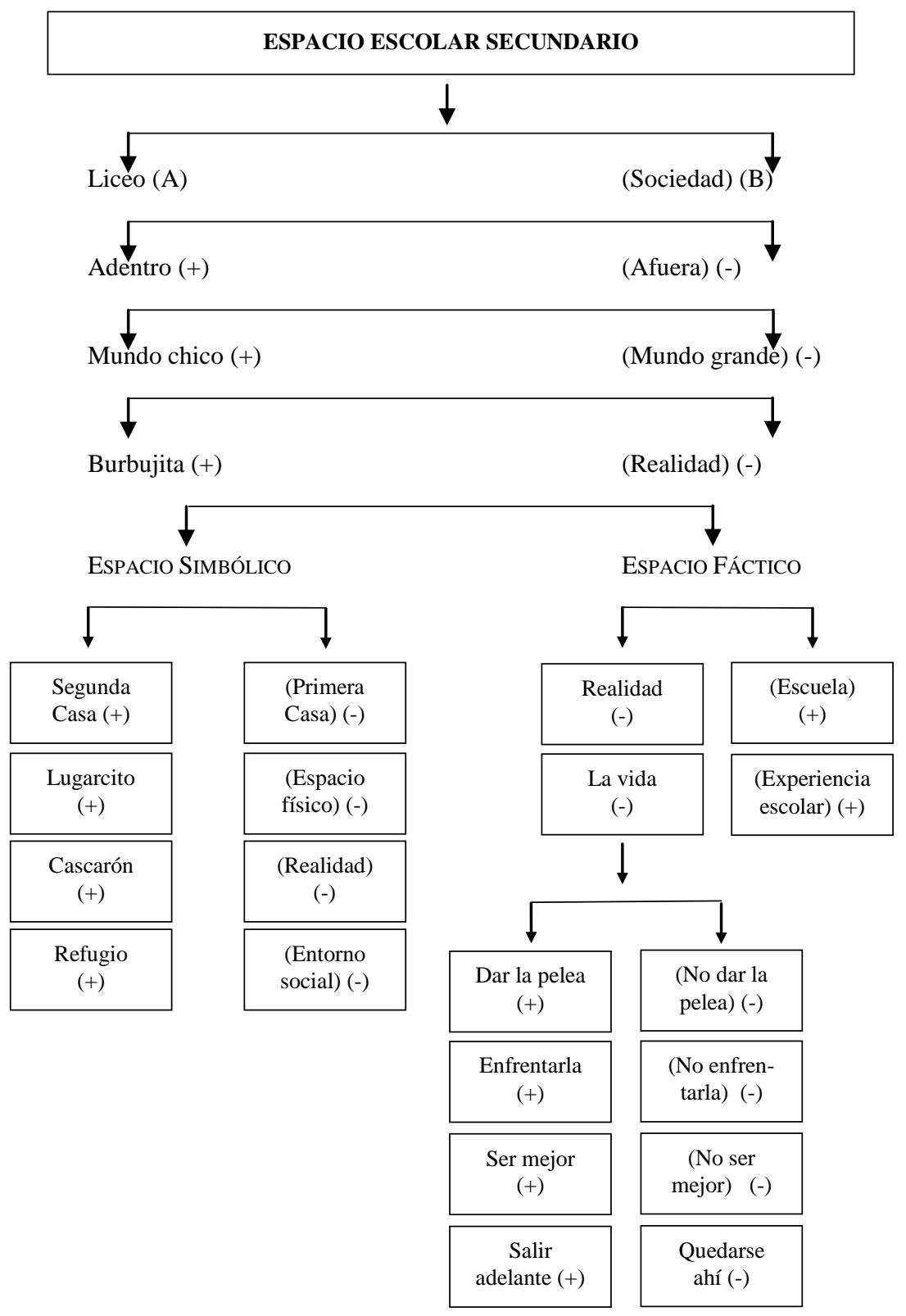


Como se puede observar, en el conjunto de estructuras semánticas paralelas antes descritas se reafirma que el eje semántico espacial se construye en torno a una primera disyunción que opone liceo v/s sociedad. En esta oposición el término «A» liceo, es simbolizado como un «adentro», como un espacio social íntimo y próximo a la experiencia de los estudiantes. Por otra parte, la sociedad emerge como un «afuera», como una exterioridad donde lo social (la vida) es connotado por los estudiantes como un lugar o escenario futuro lleno de amenazas e incertidumbres difíciles de enfrentar por parte de los y las jóvenes estudiantes. Adicionalmente, en dichas estructuras paralelas los términos «A» indican que el liceo es percibido como un «mundo chico», «un cascarón» o «una burbujita» que es valorizada como un espacio social íntimo y como «lugar» de encuentro de los actores socioeducativos. Estos significados se condensan en una totalidad común (TC), o eje semántico que hemos denominado «espacio escolar simbólico», el cual da origen a un conjunto de estructuras semánticas subordinadas donde el «liceo municipal» emerge como un espacio que le permite a los estudiantes hacer frente a las inseguridades y riesgos del «mundo exterior»; es decir, la sociedad, el «mundo grande» y por consiguiente enfrentar (o resistir) la realidad que habita cotidianamente.

En este mismo contexto analítico, podemos sostener que el liceo público municipal en el discurso de los estudiantes emerge como un espacio social que genera arraigo y simultáneamente es significado como un «refugio»; independientemente de las carencias en su infraestructura física y de la baja calidad de los logros académicos al finalizar el ciclo educativo. Por consiguiente, el liceo es percibido - en términos generales por los estudiantes - como una espacialidad en la cual los estudiantes se sienten seguros, arraigados y sus prácticas escolares cotidianas dan cuenta de una participación activa en la configuración de su propia dinámica educativa y de su funcionamiento interno.

En esta dirección incluso existe la percepción de que en términos de rendimiento académico potencial «todo depende de uno [...] nosotros somos los que hacemos el liceo» (E1, SR, Cinthya, p. 18). Lo que permite sostener que esta «voluntad de poder» juega un rol clave en la configuración de las representaciones sociales del sentido de la enseñanza media y ello opera como un elemento mediador en la internalización que los estudiantes hacen de los diagnósticos sobre «la crisis de sentido» de la educación media, de su funcionalidad y de su debilitamiento como mecanismos de integración social efectivo. 
En relación a los términos « $\mathrm{B}$ » del eje semántico antes analizado, $\mathrm{y}$ que se articulan en torno al lexema «sociedad» podemos destacar que este término es connotado como una exterioridad, un «mundo grande» que da cuenta de la realidad circundante en la cual se insertan obligatoriamente los estudiantes. Los términos, o lexemas, que dan cuenta de esta realidad dan origen a una nueva estructura semántica subordinada y cuya totalidad común (TC) que hemos denominado «espacio fáctico» y que se expresa en una serie de estructuras paralelas que se oponen radicalmente: «la realidad»/《la escuela»; «la vida»/«la experiencia escolar». En estas oposiciones, «la sociedad» es representada en términos de un «afuera» o el «mundo exterior» al liceo municipal. Esta forma de espacialidad tiene las connotaciones de una materialidad o de realidad independiente del sujeto y que en consecuencia los estudiantes no controlan y les amenaza. Frente a esta realidad, el discurso de los jóvenes enuncia diversas formas de relación o resistencia: «enfrentarla», «dar la pelea», «ser mejor»y «salir adelante» en la vida. Como podemos observar, en estos discursos destacan dos términos de la disyunción espacial. Por un parte, el liceo municipal es visto como «lugar de protección» desde el cual se construyen los sentidos educativos sobre la enseñanza media. Y simultáneamente, es simbolizado como «lugar de resistencia» frente a una espacialidad «externa» («la sociedad») que le pone incertidumbres a sus horizontes de futuro. En este contexto, «el liceo» es símbolo de refugio y espacio de acogida; es decir, un «lugar», mientras que el segundo término de la oposición semántica es la «sociedad», un espacio exterior que se construye al margen del espacio escolar (y familiar) y está representado como una espacialidad que genera incertidumbres e inseguridades derivadas de las fracturas, grietas y fallas sistémicas que impactan en la subjetividad configurando al liceo público municipal como un «lugar de refugio».

\section{b) Análisis de metáforas sobre el liceo público municipal en Chile}

Las expresiones metafóricas que se presentan a continuación son una respuesta espontánea a la siguiente pregunta incluida en el guión de entrevistas que se utilizó en el marco de esta investigación: ¿Sabes lo que es una metáfora? Cuando la respuesta fue positiva, se les pidió a los mismos estudiantes que elaboraran una metáfora que refleje cómo es el liceo municipal en el cual estudian. Los ejemplos seleccionados son los siguientes. 
- Es como un computador (LMLC).

- Es un sueño sin resolver (LMLC).

- Yo creo que es algo que ojalá nunca se dejara de pulir (LMLC).

- Es como un refugio donde podís desarrollarte tranquilo (LMLC).

- Es una planta en crecimiento que entre más se riegue o más se le dé agua, crece, entonces eso es lo más importante... capaz de aceptar a todos los insectos (LMLF).

- A ver (I) es como la libertad (LMLP)

- Es como el florero, las flores representan los alumnos y profesores (LMLP).

- Este liceo viene siendo un templo en el cual lo sagrado de la educación se demuestra sin palabras (LMLP).

- Es como que hay dos mundos totalmente diferentes (LMSR).

- Este liceo es como (I) como Windows 98 primera edición, porque cuando salió Windows 98 tenía fallas, y para arreglarlo tuvieron que ponerle parches (LMSR).

A continuación presentamos un análisis semántico estructural de las metáforas recogidas en los cuatro liceos municipales considerados en este estudio análisis. Para el caso del liceo municipal de Las Condes los textos producidos por lo estudiantes son las siguientes.

Es un sueño sin resolver.

Este liceo es un sueño sin resolver, es como algo irreal porque no todos lo van a resolver, porque no tienen armas, por ejemplo: yo tengo una compañera que va de kínder en este colegio y quiere estudiar Psicología y todos sabemos que no tiene base académica, no tiene ni la base ni esa preparación constante que se necesita p'estudiar en la universidad, como que se estresa por nada, p'mi es un sueño sin resolver, porque no todos van a lograr lo que quieren o sueñan en su vida, ya sea entrar a la Universidad o p'asegurarse un futuro laboral (E7, LC, Nicolás, p. 13).

Yo creo que es algo que ojalá nunca se dejara de pulir.

Yo creo que es algo que ojalá nunca se dejara de pulir, de limpiar, de renovar, de ir metiendo cosas nuevas, conocimientos todo lo que este vigente, valores, o sea (I) que nunca, ojalá que nunca parara de ir formándose, de eso se trata también (I) o sea los tiempos van cambiando, la educación cambia, o sea (I) estar abiertos a los conocimientos en general, que no sea fijo, y en relación a lo externo del colegio, o sea que se vaya también recogiendo la información externa, las nuevas cosas y conocimientos que van surgiendo, que no se quede estancado en una cosa. (I) que no se quede pegado en el prejuicio que es malo y no salgamos de eso... porque el colegio lo hacemos nosotros también» (E1, LC, Andrea). 
Es como un refugio.

Es como, es que para mí es como un refugio donde podís desarrollarte tranquilo, como en paz, ser tu mismo acá, cachai, si te querí pegar en el suelo con el piano y hacerlo nadie te va a decir oye no hagai eso, cachai nadie te va a limitar, porque ellos dejan que uno se desarrolle, me entendí, no te matan la pasión, porque hay colegios que te dicen esto y esto otro... te reprimen, eso podría decir de este liceo (E4, LC, Francisca).

Es como un computador.

A ver (I) no sé (I) este liceo es como (-) este liceo es como un computador; porque si quiere uno juega y si quiere uno se mete a internet y se instruye, es como muy complicado (I) porque si uno quiere, uno puede estar todo el día jugando o si uno quiere también, puede estar todo el día buscando información que esta ahí, y de ahí cambia al juego. Las dos opciones están allí y depende de ti mismo porque tu manejai el mouse (E5, LC, Sergio, p. 14).

De los textos anteriormente presentados, hemos seleccionado para el análisis la siguiente metáfora: «es un sueño sin resolver». Las estructuras semánticas paralelas y sus respectivas valorizaciones (+ 0 derivadas de esta metáfora son las siguientes.

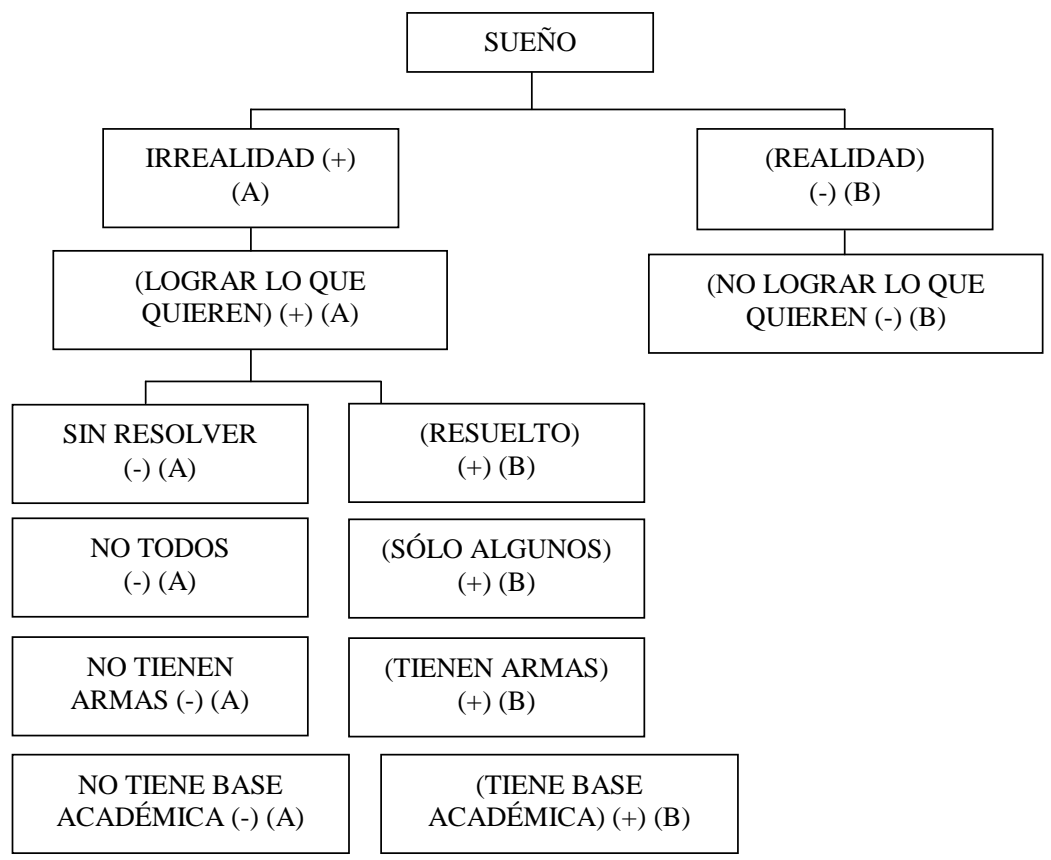


Como podemos observar, las estructuras semánticas anteriormente presentadas se construyen sobre una oposición de base: irrealidad/ (realidad). Y consecuentemente, en esta estructura paralela los términos «A» indican que el liceo es connotado por los estudiantes como un sueño, como una aspiración de lograr lo que se quiere en la vida. Por su parte, la realidad es definida como el escenario exterior donde se encuentran las restricciones y obstáculos que impiden el logro de dichos sueños o aspiraciones en la vida. A partir del lexema sueño, surge una estructura semántica jerarquizada o subordinada que indica claramente que este sueño no tiene solución para la mayoría (o no todos) de los estudiantes de liceos municipales. En estas estructuras subordinadas, surge una de las claves semánticas que permitirían resolver el sueño: la base académica. Esta es una de las armas que permitiría a los estudiantes transitar del sueño a la realidad, de las aspiraciones y deseos al logro concreto de sus expectativas para su vida futura.

El segundo caso de análisis corresponde a la siguiente metáfora elaborada por un estudiante de un liceo municipal de La Florida: «El liceo es como una planta... entre más se riegue o más se le dé agua, más crece... aparte que es capaz de aceptar a cualquier insecto».

El liceo sería como, a ver, déjame pensar (II) no sé, aparte que es como (-) el liceo es como una planta viva, es una planta en crecimiento que entre más se riegue o más se le dé agua, más crece, entonces eso es lo más importante, y aparte que es capaz de aceptar a cualquier insecto, o cosas así, no necesariamente significa que seamos insectos, pero se puede ver de esa forma. Pero si en algún momento se le deja de (I) regar o se olvida la planta se marchita... ¿Cómo se puede cuidar?... De (-) haber, puede ser más, no sé depende de la preocupación más del director, o de los profesores, que lleguen alumnos interesados, así que se preocupen, sería como el agua... como que den una buena impresión del liceo, entonces allí le va a dar fama, entonces va a tener más alumnos. Pero si eso no pasa, si no le exigen a los alumnos esto van a... son como la base del liceo, entonces igual es un lugar donde estamos estudiando y todo, entonces si no le damos importancia se puede destruir, se puede marchitar (E6, LF, Sebastián, p. 18).

Como una forma de contextualizar el análisis de esta metáfora queremos recordar que en el caso de este liceo, los estudiantes han construido previamente una representación social del sentido de la enseñanza secundaria municipal que hemos denominado como «fórmate como persona» (Molina, 2008). Lo cual indica que lo más relevante 
para los y las jóvenes que asisten a este liceo resulta ser el desafío de «ser más responsables», «ser independientes» $\mathrm{y}$ «madurar»y «dejar de ser niños», entre otros sentidos más relevantes.

En relación al análisis de la metáfora antes indicada hemos identificado las siguientes estructuras semánticas paralelas.

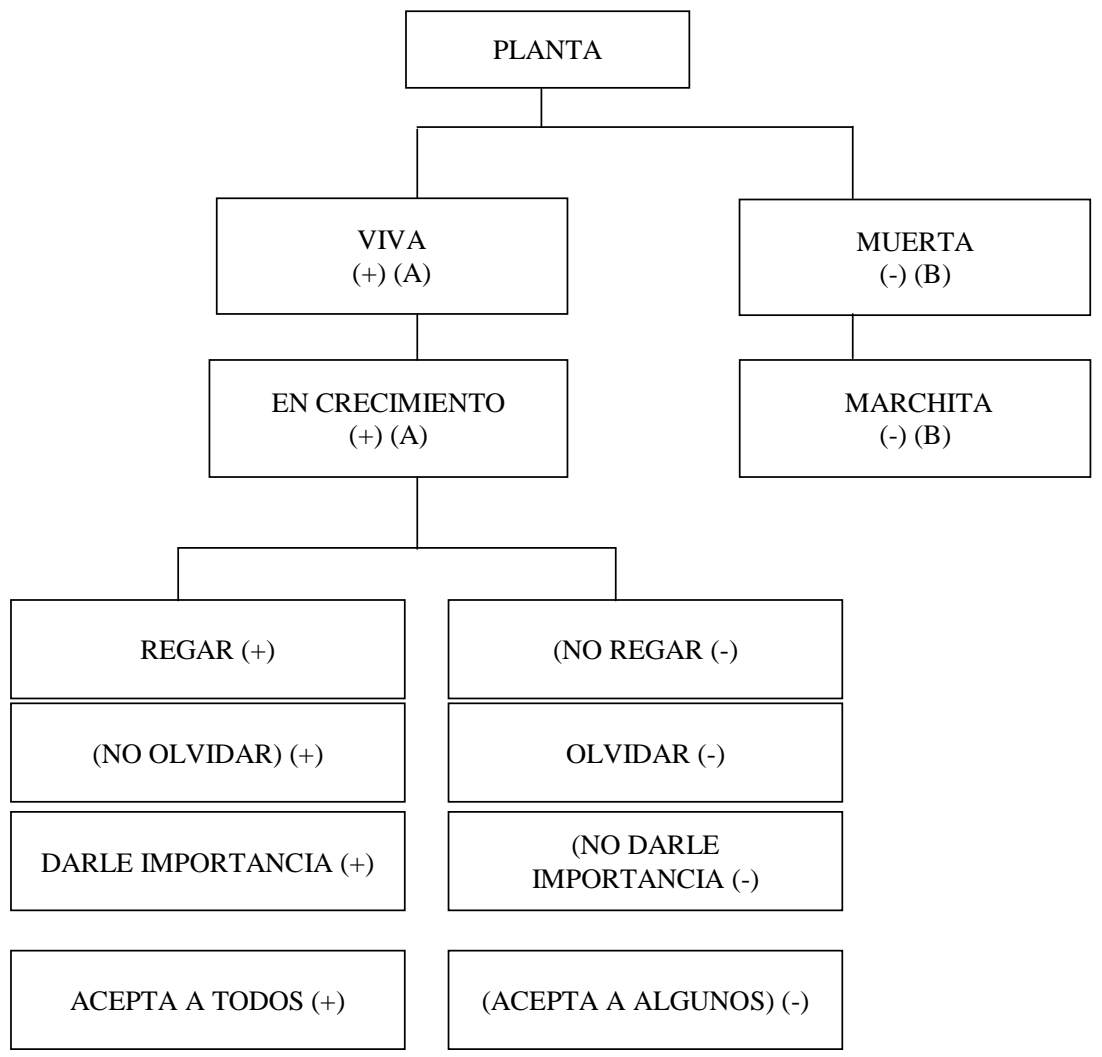

Esta comparación está construida sobre un eje semántico que opone: planta viva/planta muerta. A partir de una metáfora del mundo natural, se intenta reflejar que el liceo es un lugar y espacio más bien simbólico, que requiere un permanente cuidado por parte de sus diferentes actores y habitantes de la planta. Estos cuidados se expresan en las siguientes disyunciones: regar/no regar; olvidar/no olvidar; darle importancia/no darle importancia. Estas estructuras semánticas paralelas y sus respectivos términos nos remiten a un significado asociado a la idea de cuidado, que los diferentes actores del liceo municipal tienen 
que proveerle a este lugar de desarrollo y crecimiento personal de los alumnos que la habitan. Por el contrario, al igual que una planta, puede marchitarse y finalmente morir. Finalmente, en el conjunto del texto analizado emerge una valorización global positiva del liceo municipal por cuanto, y tal como señala un estudiante el liceo, es como una planta que «es capaz de aceptar a cualquier insecto» y aunque se aclara que no significa que los estudiantes sean unos insectos, pero metafóricamente hace referencia a la ausencia de mecanismos o estrategias de selección y de discriminación de los estudiantes al interior del liceo municipal.

El tercer caso de análisis corresponde a las metáforas elaboradas por estudiantes que asisten al liceo municipal de La Pintana y los textos seleccionados son los siguientes:

\section{Es como la libertad.}

A ver (I) es como la libertad...(-) es más libre y deja más a la mentalidad de uno, lo deja pensar a uno, deja crear tus propias ideas, tus propias filosofías de vida, como que lo dejan ser a uno y no andan urgiendo tu vas a ser así o así. Como que te dejan tiempo pa hacer las cosas pa pensar, p'conversar, p'estudiar lo que a uno le interesa, también p'informarse y así tener más cultura. No es pura materia, así como por pasarla no más. A eso me refiero con la libertad (-) lo que pasa es que yo he estado por varios liceos, y ahora cuarto medio acá. La imagen que me dejó este liceo, es que se puede conversar con los profes, y eso ayuda caleta p'saber conversar con otras personas, además aquí se valoran los secretos de las personas que le cuentan, valorar la confianza, valorar lo que puede llegar a durar con una persona que esta recién conociendo y valorar a los amigos y la pareja, y valorarlas. Esas cinco cosas me ha dejado este liceo. Las materias y profes no, es que EN LOS LICEOS ES TODO LO MISMO, todo es lo mismo. Este liceo es más libre que otros en los que he estado (E8, LP, Daniel).

Es como el florero, las flores representan los alumnos y profesores.

Es como el florero, las flores representan los alumnos y profesores. Pero a lo mejor esas flores a mitad de año van a estar malas que son los alumnos, y algunas están buenas y quizás se contaminan y el agua hace falta que algunas personas boten el agua podrida y cambien las flores, que alguien se preocupe. Para mí las flores tienen hartos colores, y se ve futuro, pero falta preocupación, de los rangos más altos, el director hasta el profesor. El director debería preocuparse de hablar con los profesores y decirles en que aspectos están mal, en lo que hay que cambiar, en preocuparse harto para mejorar (E4, LP, Soraya, p. 11). 
Este liceo viene siendo un templo en el cual lo sagrado de la educación se demuestra sin palabras.

Este liceo viene siendo un templo en el cual lo sagrado de la educación se demuestra sin palabras, sin hechos, solo con ver. Yo veo educación, veo a mis amigos, veo a los profesores de repente afuera de clases enseñando sin palabras, con una sonrisa, con un gesto amable, veo educación en como un templo, porque LA EDUCACIÓN ES ALGO SAGRADO QUE TODOS TENEMOS DERECHO. Y así veo al liceo (E6, LP, Leandro, p. 12).

De los textos anteriormente presentados se ha seleccionado para el análisis la siguiente comparación sobre el liceo municipal: «Es como la libertad». El análisis semántico estructural del texto completo de esta expresión metafórica nos permitió identificar las siguientes oposiciones de base: es más libre/(menos libre); deja pensar/no deja pensar; dejan ser/no dejan ser. Estas oposiciones se sintetizan claramente en la expresión de un estudiante que dice lo siguiente «como que lo dejan ser a uno y no andan urgiendo tu vas a ser así o así». Al respecto cabe recordar que dicha metáfora sobre el liceo público municipal se relaciona con una representación social del sentido de la enseñanza media municipal que según Molina (2008) se denomina «Tener más cultura» y que corresponde a una de las experiencias de escolarización secundaria propia de liceos con bajos niveles de logros educativos y con mayores dificultades para responder a las expectativas de inserción social de sus estudiantes. A partir de los términos y lexemas contenidos en la metáfora antes indicada se ha construido la respectiva estructura semántica paralela que se articula en torno a la noción de libertad como eje de significados.

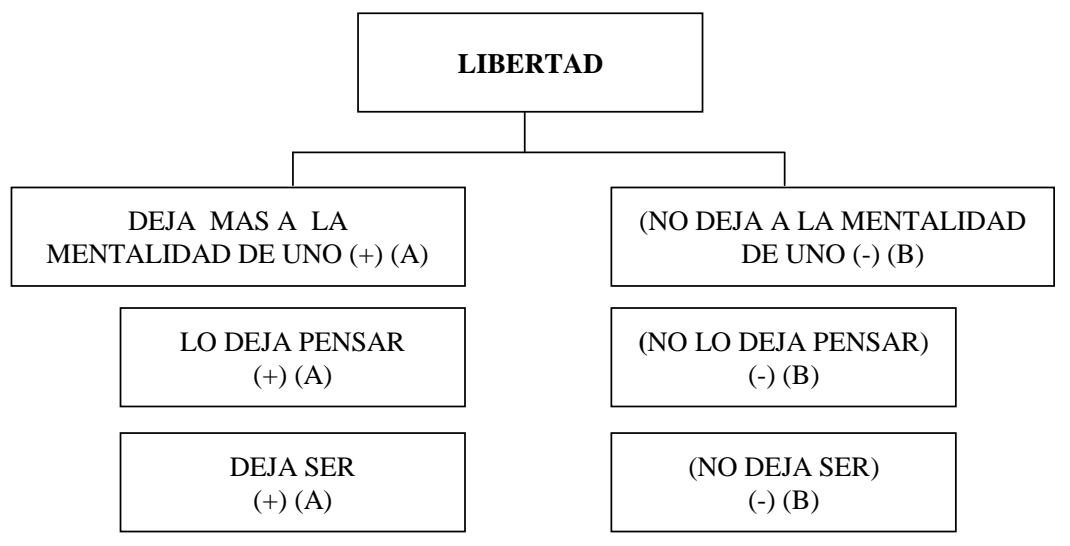


Como podemos observar, esta comparación está construida sobre un eje semántico denominado «libertad» y cuyas oposiciones son las siguientes: Deja pensar/no deja pensar; deja ser/no deja ser. Es decir, el liceo en este caso se convierte en un espacio simbólico y material de ejercicio de la libertad, de la necesidad de expresar la singularidad identitaria de los estudiantes. Tal vez la valoración de esta dimensión del liceo, esconde la carencia de espacios de libertad en otros ámbitos de la experiencia social de los jóvenes: la familia, la comunidad y los espacios públicos en los cuales se encuentran con sus pares. Por otra parte, la fuente de valoración global que construyen el estudiante entrevistado sobre el liceo municipal se refiere a los bajos niveles de control disciplinario que los estudiantes perciben. Se trata de un espacio que les permite individualizarse, tener sus propias ideas y formas de expresarse al interior del espacio escolar. Como podemos colegir, estos elementos valorados son parcialmente congruentes con la representación del sentido de la enseñanza media construida en el liceo municipal de La Pintana: «tener más cultura». Como se indicó anteriormente, estos estudiantes no valoran son tanto los aspectos instrumentales, académicos y cognitivos, de la enseñanza municipal; es decir, «las materias» o los «contenidos», sino la dimensión más informativa, formativa, y los conocimientos genéricos (cultura) vinculados al acceso a información de interés general, y que por diversos factores no están disponibles en los entornos familiares y comunitarios en los que se desenvuelven cotidianamente dichos estudiantes. El conjunto de estos elementos son los que configuran un espacio relacional connotado como «Lugar de libertad» y que es lo que a la postre es el aspecto más valorado en este liceo de la zona sur de Santiago.

El cuarto caso de análisis corresponde a las metáforas recopiladas en el liceo municipal de San Ramón, los textos seleccionados son los siguientes: «Es como que hay dos mundos totalmente diferentes».

Una imagen (II) esta misma sala po' (II) es como que hay dos mundos totalmente diferentes. No sé, es que aquí hay (indica un sector de atrás de la sala de clases donde estamos realizando la entrevista) un grupito de los que no hacen nada y los otros allá (indica la parte delantera de la sala de clases) que hacen todo. Yo estoy entre medio, pero es impresionante los que no hacen nada, porque no sé, es súper heavy, porque no tienen nada con la vida, pasan en nada. Y no se puede hacer clases y ellos no lo hacen conscientes interrumpiendo la clase, sino sale, y sale, sale, yo creo que no dicen iya voy a interrumpir la clase para que no trabajemos tanto! [...] pero no es así, es un desorden espontáneo, que no 
les permite pensar lo que están haciendo, pero es constante, es como nunca están ahí en la clase, y siempre es así...son los flojos. ¿YY el otro grupo o el otro mundo? Son los «mateitos» [sic], que son como tres. Y ellos son los que quieren salir adelante, no quieren estar acá y después quieren ir a la U (E1, SR, Cinthya, p. 19).

Este liceo es como (I) como Windows 98 primera edición, porque cuando salió Windows 98 tenía fallas, y para arreglarlo tuvieron que ponerle parches. Este liceo tiene fallas y cuando lo arreglan echan parches, entonces mal arreglado funciona mal. A eso lo comparo yo el liceo municipal (E8, SR, Pablo, p. 12).

Para efectos del análisis hemos seleccionado la siguiente metáfora: «Es como que hay dos mundos totalmente diferentes». A partir de este texto se ha construido la siguiente estructura semántica paralela y sus respectivos ejes de significado subordinados.

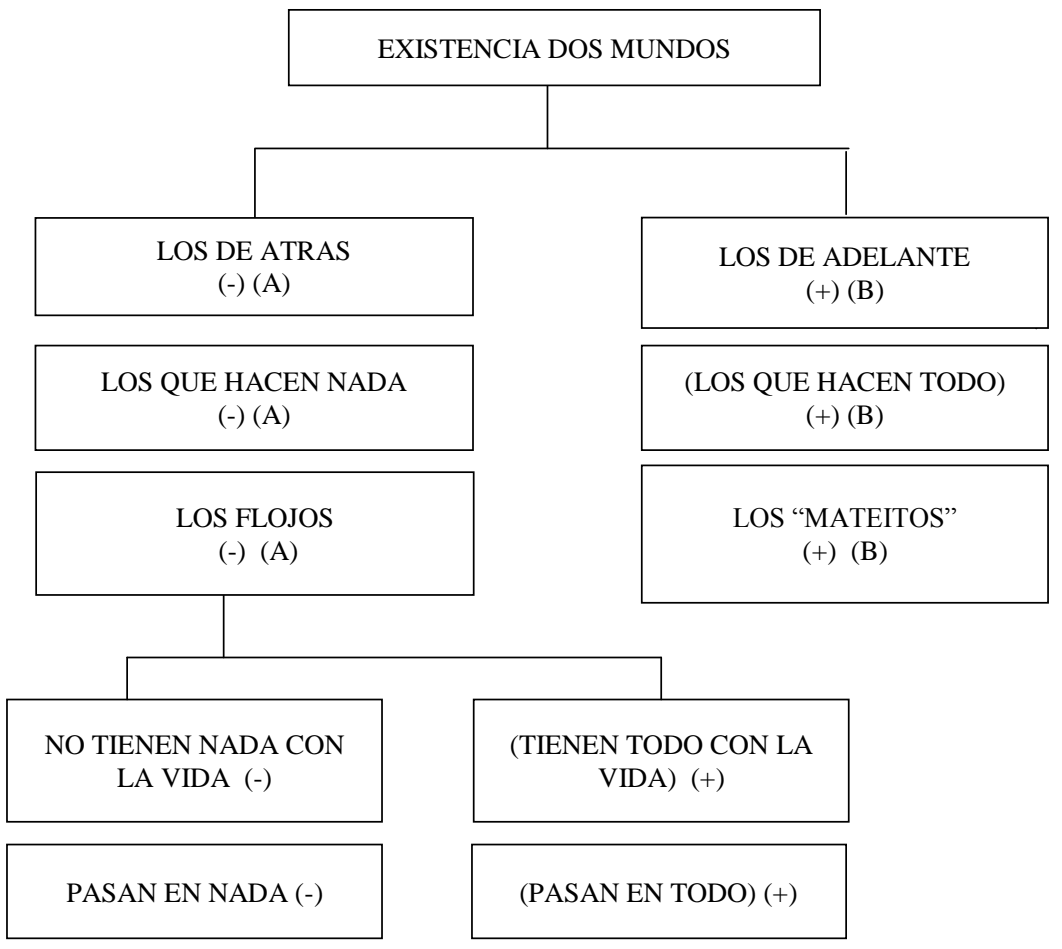


En términos generales podemos señalar que a partir de las estructuras semánticas identificadas en esta metáfora, los términos «A» de la estructura paralela están claramente anclados en la sala de clases (aula) del liceo municipal, el cual se constituye en un espacio cotidiano y «lugarizado» que se encuentra fracturado entre dos mundos simbólicos: «los de atrás» v/s «los de adelante»; «los que hacen todo» v/s «los que hacen nada». Ambos términos son indicativos de una polarización de los horizontes de sentido, no tanto entre diferentes liceos, sino al interior de una misma aula o sala de clases. Unos estudiantes están orientados por una «racionalidad» más instrumental («Prepararte para el futuro») y otros, guiados por una «lógica de acción» más expresiva y centrada en vivir la experiencia escolar como un valor en sí mismo y prerrequisito de la condición juvenil («Vivir el presente»).

Lo anterior, pone en cuestión la fuerza normativa del liceo municipal y la capacidad relacional de los diferentes actores del mundo educativo. Por una parte, evidencia la incapacidad de los profesores de incorporar a todos los estudiantes a las tareas y el trabajo propiamente escolar; que es uno de los aspectos centrales de su formación y de su práctica pedagógica. Desde otro ángulo, los estudiantes al describir está representación social del sentido de la enseñanza municipal y que hemos denominado «vivir el presente» señalan lo siguiente: «pero aquí nadie pesca, es puro desorden, puro leseo, es como que todos se dedican a puro vivir el momento en la sala [de clases], cero responsabilidad, cero estudio, salvo contadas ocasiones, y con ciertos profes y es como que sólo en algunos momentos esto se transforma en una verdadera escuela» (E1, SR, Cinthya, p. 24). En este texto, los estudiantes ponen de manifiesto su propia incapacidad relacional y los obstáculos cotidianos que existen para constituirse como sujetos y actores de su propia escolarización con capacidad de influir en la gestión tanto de «sí mismos» y como de influir en los «otros», en pos la convivencia escolar.

\section{CONCLUSIONES}

En términos globales se observa que las valorizaciones realizadas por los estudiantes entrevistados sobre la enseñanza media municipal en general y específicamente sobre el liceo municipal, se polarizan hacia alguno de los cuatro horizontes de sentido identificados en la literatura (Molina, 2008) en la región metropolitana de Santiago de Chile: prepararte para el futuro; formarte como persona, tener más cultura y vivir la experiencia (escolar). Al respecto, cabe destacar, que en los 
textos producidos por los estudiantes, al enunciar sus valorizaciones a través de una metáfora o comparaciones, con ellas se logra dar cuenta, «espontáneamente» de los aspectos que subjetivamente más valoran o rechazan de la enseñanza media y de su expresión materializada en el liceo público municipal. Por ejemplo, para el caso del liceo de Las condes, la representación social sobre el sentido de la enseñanza municipal al estar centrada sobre un eje instrumental (prepararte para el futuro) da origen a unas metáforas muy expresivas y propias de una lógica de acción escolar más instrumental o estratégica y por ello, las metáforas formuladas por los estudiantes apuntan a destacar que el liceo al cual asisten, y la enseñanza media en su conjunto, constituyen un sueño sin resolver. Lo mismo tiende a ocurrir con las demás metáforas analizadas para cada caso en estudio, es decir, es posible establecer una correspondencia parcial, aunque no lineal, con las diferentes representaciones sociales del sentido al cual están ancladas simbólicamente las metáforas elaboradas por los estudiantes que asisten cotidianamente a los liceos público municipales en el Chile contemporáneo.

En el complejo escenario de trasformaciones económicas, sociales y culturales que vive la sociedad chilena actual, se sostiene que la emergencia de nuevas configuraciones de sentidos sobre la educación secundaria pública-municipal; y que se expresan simbólicamente en las metáforas analizadas en este artículo («Un sueño sin resolver», «Una planta», «Es como la libertad»y «Existencia de dos mundos»), permite concluir que el liceo público municipal, pese a su actuales insuficiencias, se constituye en un potente elemento mediador entre la experiencia escolar de los miles de estudiantes que asisten cotidianamente a sus aulas y las políticas educativas orientadas a rescatar la educación pública como elemento esencial de la recomposición del vinculo social en la sociedad chilena actual. Sin embargo, y tal como señala Sobrero (2011), ello requiere un nuevo modo de pensar las políticas educativas públicas, de modo tal que recuperen su carácter político y transparenten el régimen de la mirada y de su relación con el sistema de regulación social en el que se inscribe y al cual promueven en un momento histórico determinado. Lo anterior, permitiría desplazar las cotas actuales de la conversación social sobre educación pública en Chile y cuyos ejes semánticos son; más o menos descentralización administrativa, gestión recursos con mayor o menor eficiencia, «libertad», o restricciones para despedir profesores y por supuesto, una medición (semaforización) de la calidad educativa, vinculada unidimensionalmente a la cuantificación de aprendizajes en 
base a pruebas estandarizadas; todo lo cual constriñe peligrosamente los horizontes de sentido de la educación pública chilena actual.

Finalmente, resulta relevante reconocer la pluralidad de sentidos que emergen cotidianamente desde la experiencia escolar de los estudiantes secundarios que asisten a la enseñanza media públicamunicipal en Chile, por cuanto es urgente que las políticas educativas dirigidas a este nivel educativo se orienten y promuevan, en un futuro inmediato, acciones con una verdadera mirada pública que permitan integrar dichos sentidos y metáforas educativas en el rediseño y renovación estratégica de la enseñanza media chilena en el corto plazo. Dichas acciones se enfrentarán con una paradoja central identificada en el discurso de los estudiantes, quienes coinciden en que la enseñanza media tiene como principal sentido el «prepararse para el futuro», no obstante ello y tal como hemos revisado anteriormente; los actuales niveles de logro académico y los evidentes conflictos entre culturas escolares y culturas juveniles, amenazan seriamente el cumplimiento de dicho sentido primario destacado por las y los jóvenes estudiantes que asisten a escuelas secundarias públicas en Chile. En la perspectiva de superar esta paradoja, la educación pública tendría entre sus principales desafíos de corto y mediano plazo la tarea de (re)construir el carisma y la fuerza movilizadora que tuvo la enseñanza secundaria pública en momentos claves del desarrollo de la sociedad chilena contemporánea.

PunTA ARENAS (CHILE), MARZO 2013

RECIBIDO: MARZO 2013

ACEPTADO: ABRIL 2013 


\section{REFERENCIAS BIBLIOGRÁFICAS}

Aguilera, ÓsCAR (2009): «Los estudios sobre juventud en Chile. Coordenadas para un estado del arte». Última Década $\mathrm{N}^{\circ} 31$. Valparaíso: Ediciones CIDPA.

Araujo, KathYa y Danilo Martucelli: (2012). Desafios comunes. Retrato de la sociedad chilena y sus individuos. Tomo I. Neoliberalismo, democratización y lazo social. Santiago: LOM.

BAEZA, JORGE (2001): El oficio de ser alumno en jóvenes de liceo de sector popular. Santiago: Universidad Católica Silva Henríquez.

CANALES, MANUEL (1994): El estudio de la realidad social con metodologías cualitativas. Santiago: Ministerio Secretaría General de Gobierno, División de Organizaciones Sociales.

Cerda, Ana María, Jenny AssaÉl, Florencio Cevallos y Rodrigo SEPÚLVEDA (2000): Joven y alumno: ¿conflicto de identidad? Un estudio etnográfico en los liceos de sectores populares. Santiago: Ediciones LOM y PIIE.

DÁVILA, ÓsCAR, FeliPe GHIARdo y CARLos MEDRANo (2005): Los desheredados. Trayectorias de vida y nuevas condiciones juveniles. Valparaíso: Ediciones CIDPA.

DuARTE, Claudio (2000): «iJuventud o juventudes? Acerca de cómo mirar y remirar a las juventudes de nuestro continente». Última Década $\mathrm{N}^{\circ} 13$. Valparaíso: Ediciones CIDPA.

DUBET, FRANCOIS (2004): «La juventud». En: Historia de la humanidad. El siglo XX. La globalización de las culturas. Madrid: UNESCO-PLANETA.

EDWARDS, VERÓNICA (1995): El liceo por dentro. Estudio etnográfico sobre prácticas de trabajo en educación media. Santiago: Ministerio de Educación.

GARRETÓN, MANUEL ANTONIO (2000): La sociedad en que vivi(re)mos. Introducción sociológica al cambio de siglo. Santiago de Chile: LOM.

GARRIDO, MARCELO (2009): La espesura del lugar. Reflexiones sobre el espacio en el mundo educativo. Santiago: Universidad Academia de Humanismo Cristiana.

GIMENO, JosÉ (2001: La educación obligatoria: su sentido educativo y social. Madrid: Morata.

GREIMAS, ALGIRDAS JULIEN (1971: Semántica estructural. Investigación metodológica. Madrid: Gredos.

KESSLER, GABRIEL (2002): La experiencia escolar fragmentada. Estudiantes y docentes en la escuela media de Buenos Aires. Argentina: IIPE-UNESCO.

KRAUSKOPF, DINA (2011): «Enfoques y dimensiones para el desarrollo de indicadores de Juventud orientados a su inclusión social y calidad de vida». Última Década No34. Valparaíso: Ediciones CIDPA.

LAKOFF, GEORGE y MARK JOHNSON (2001): Metáforas de la vida cotidiana. Madrid: Cátedra. 
MolinA, WALter (2008): «Sentidos de la enseñanza media desde la experiencia escolar de estudiantes de liceos municipales». Estudios Pedagógicos, Vol. XXXIV, Nº1. Valdivia: Universidad Austral de Chile.

- y MARIO SALDOVAL (2006): «Cultura escolar y cultura juvenil: la (re)construcción simbólica del espacio escolar en la mutación cultural». Temas Sociológicos No11. Santiago: Universidad Católica Silva Henríquez.

OYARZÚN, ÁSTRID, RAÚl IRRÁZABAL, IGOR GOICOVIC y LEONORA REYES (2001): Entre jóvenes reproductores y jóvenes co-constructores: sentidos de la integración en la cultura escolar. Valparaíso: Ediciones CIDPA.

SANDOVAL, MARIO (2002): Jóvenes en el siglo XXI. Sujetos y actores en una sociedad en cambio. Santiago de Chile: Ediciones Universidad Cardenal Silva Henríquez.

SALINAS, ÁlVARO y ABRAHAM FRANSSEN (1997): El zoológico y la selva. La experiencia cultural de los jóvenes de fin de siglo. Santiago: Centro de Investigación y Desarrollo de la Educación.

SOBRERO, VIVIANA (2011): «Configuraciones de sentido en torno a la educación pública en Chile. Análisis de las continuidades y desplazamientos de sentido en torno a la educación pública, en los discursos de la política educativa a partir de 1990». Tesis para optar al grado académico de doctora en ciencias de la educación. Santiago: Pontificia Universidad Católica de Chile.

Ruíz, SOlEDAD, RoBERTO ACEITUNO, ANA MARÍA UgARTE, ÁlVARO JiMÉNEZ, ALEJANDRA REINOSO y RODRIGO ASÚN (2011): «Jóvenes secundarios de hoy: estudio sobre su visión de la sociedad desde los conceptos de anomia y alienación psicosocial». Última Década №34. Valparaíso: Ediciones CIDPA.

TENTI, EMILIO (2000): Culturas juveniles y cultura escolar. Buenos Aires: UNESCO.

TOURAINE, AlAN (1997): ¿Podremos vivir juntos? Iguales y diferentes. Buenos Aires: Fondo de Cultura Económica.

ZARZURI, RAÚL y RODRIGO GANTER (2002): Culturas juveniles, narrativas minoritarias y estéticas del descontento. Santiago: Universidad Católica Cardenal Silva Henríquez. 